\title{
A practical and adaptive approach to lung cancer screening: a review of international evidence and position on CT lung cancer screening in the Singaporean population by the College of Radiologists Singapore
}

Charlene Jin Yee Liew ${ }^{1}$, FRCR, Lester Chee Hao Leong' ${ }^{2}$, FRCR, Lynette Li San $\underline{T e O}^{3}$, FRCR, Ching Ching $\underline{\text { Ong }}^{3}$, FRCR, Foong Koon $\underline{C h e a h}^{2}$, FRCR, Wei Ping $\underline{\text { Tham }}^{2}$, FRCR, Haja Mohamed Mohideen Salahudeen ${ }^{2}$, FRCR, Chau Hung $\underline{\text { Lee }}^{4}$, FRCR, Gregory Jon Leng Kaw ${ }^{4}$, FRCR, Augustine Kim Huat Tee ${ }^{5}$, FRCP, lan Yu Yan Tsou ${ }^{6}$, FRCR, Kiang Hiong Tay ${ }^{2}$, FRCR, Raymond $\underline{\text { Quah }}{ }^{7}$, FRCR, Bien Peng $\underline{\operatorname{Tan}^{4}}$, FRCR, Hong $\underline{\mathrm{Chou}^{8}}$, FRCR, Daniel $\underline{\mathrm{Tan}}^{9}$, FRCR, Angeline Choo Choo $\underline{\mathrm{Poh}^{1}}$, FRCR, Andrew Gee Seng $\underline{\operatorname{Tan}}^{1}$, FRCR

\begin{abstract}
Lung cancer is the leading cause of cancer-related death around the world, being the top cause of cancerrelated deaths among men and the second most common cause of cancer-related deaths among women in Singapore. Currently, no screening programme for lung cancer exists in Singapore. Since there is mounting evidence indicating a different epidemiology of lung cancer in Asian countries, including Singapore, compared to the rest of the world, a unique and adaptive approach must be taken for a screening programme to be successful at reducing mortality while maintaining cost-effectiveness and a favourable risk-benefit ratio. This review article promotes the use of low-dose computed tomography of the chest and explores the radiological challenges and future directions.
\end{abstract}

Keywords: computed tomography, lung cancer, position paper, public health, screening

\section{INTRODUCTION}

Lung cancer is the leading cause of cancer-related death among men and women worldwide. In 2012 alone, an estimated 1.59 million deaths were caused by lung cancer globally. ${ }^{(1)}$ In Singapore, it causes the most cancer-related deaths among men and the second most cancer deaths (after breast cancer) among women. In 2010-2014, lung cancer killed almost as many women as breast cancer, with 1,912 (16.4\%) deaths compared to $2,051(17.6 \%)$ from breast cancer. ${ }^{(2)}$

Although the incidence rate of lung cancer among Singaporeans has decreased since the late 1970s, where rates among men were 61.2 per 100,000 per year to 33.7 per 100,000 per year between 2010 and 2014, it remains the second most common cancer in men and the third most common cancer in women. This drop in lung cancer rates in men is likely attributable in part to the reduced prevalence of cigarette smoking. In contrast, the incidence rate of lung cancer in women has remained relatively stable since the 1970 s, at 13.9 per 100,000 per year to 11.4 per year in $2010-2014$. $^{(2)}$

The importance of screening is highlighted by the fact that $75 \%$ of patients with lung cancer present with symptoms due to advanced disease that is not amenable to cure. ${ }^{(3)}$ Despite advances in therapy, five-year survival rates remain dismal at an average of $18 \%$ for lung cancer patients. ${ }^{(3,4)}$
Since many lung cancer cases are attributed to smoking, it is crucial to implement a national smoking cessation programme in conjunction with screening. Based on United States (US) data, tobacco smoking is thought to be causal in $85 \%-90 \%$ of all lung cancers. ${ }^{(5)}$ It is thought that worldwide progress in smoking cessation is now reflected in declining lung cancer rates and mortality in men worldwide. A robust combined screening and smoking cessation programme would enable the lung screening programme to gain in mortality reduction from all causes of death related to smoking, as well as capitalise on improved cost-effectiveness due to reductions in the indirect cost of tobacco smoking in overall healthcare spending. The impact of smoking on direct and indirect costs to healthcare spending in Singapore is not insignificant and is estimated to be around SGD 839 million, based on 2002 data. ${ }^{(6)}$

\section{INTERNATIONAL LUNG SCREENING GUIDELINES AND TRIALS}

Results from the largest US lung screening trial to date, the US National Lung Screening Trial (NLST) demonstrated a relative reduction in mortality from lung cancer with low-dose computed tomography (LDCT) screening of $20 \% .^{.7-12)}$ The rate of death from any cause was reduced by $6.7 \%$ in the LDCT group.

The recommendations for this position paper are based, in part, on guidelines by the US Preventive Services Task Force

\footnotetext{
1Department of Diagnostic Radiology, Changi General Hospital, ${ }^{2}$ Department of Diagnostic Radiology, Singapore General Hospital, ${ }^{3}$ Department of Diagnostic Imaging, National University Hospital, ${ }^{4}$ Department of Diagnostic Radiology, Tan Tock Seng Hospital, ${ }^{5}$ Department of Respiratory and Critical Care Medicine, Changi General Hospital, ${ }^{6}$ Department of Diagnostic Radiology, Mount Elizabeth Hospital, ${ }^{7}$ Department of Diagnostic Radiology, Farrer Park Hospital, ${ }^{8}$ Department of Diagnostic Radiology, Khoo Teck Puat Hospital, ${ }^{9}$ Department of Diagnostic Radiology Oncology, Farrer Park Hospital, Singapore

Correspondence: Dr Charlene Liew Jin Yee, Consultant, Department of Diagnostic Radiology, Changi General Hospital, 2 Simei Street 3 , Singapore 529889. charlene.liew.j.y@singhealth.com.sg
} 
(USPSTF), which were published in 2014 and largely informed by the results of the NLST. The USPSTF recommendations support LDCT lung cancer screening for healthy adults aged 55-80 years with a smoking history of 30 pack-years or more and who have smoked within the previous 15 years. ${ }^{(13,14)}$ The total duration of screening was not specified, but screening should be discontinued once a person has not smoked for 15 years or develops a health problem that substantially limits their life expectancy or the ability to have curative lung surgery (Grade B recommendation).

In practical terms, under the US Affordable Care Act, any procedure that receives a Grade B recommendation from the USPSTF is covered by private insurers without requiring copayment. In 2015, the US federal agency Centers for Medicare and Medicaid Services (CMS) announced its decision to start covering lung cancer screening once per year under the Medicare programme for long-time smokers at high risk for the disease. During the initial screening, the beneficiary must produce a written order for LDCT lung cancer screening obtained during a lung cancer screening counselling session from a physician, physician assistant, nurse practitioner or clinical nurse specialist. The CMS also specifies radiologist and imaging centre eligibility criteria.

In Europe, there are no reimbursed screening programmes to date, but several large randomised controlled trials have emerged from European countries, such as the Dutch-Belgian NELSON trial, DLST from Denmark and Italung, DANTE and MILD from Italy. ${ }^{(15-19)}$ The European Society of Radiology (ESR) and the European Respiratory Society (ERS) published an ESR/ERS white paper in 2015 on lung cancer screening that concluded that lung cancer screening using LDCT reduces mortality and recommended lung cancer screening within a clinical trial or in routine clinical practice at certified multidisciplinary medical centres. ${ }^{(20)}$

Data is also available from two trials conducted in Japan. The Japanese studies notably included both smokers and nonsmokers in their screening cohort ${ }^{(21,22)}$ as part of community-based screening programmes. The screening programme at Hitachi Medical Center began in 2001 and screened 31,739 participants with chest computed tomography (CT) scans at least once. By 2009, an estimated $36 \%$ of Hitachi residents ages $50-79$ had undergone CT screening. For men and women ages 50-79, lung cancer mortality fell by $24 \%$. $^{(23)}$

The Japanese approach to screening non-smokers and smokers alike was successful in demonstrating that its model may reduce lung cancer deaths among non-smokers, considering that more than half of the study participants were non-smokers and $60 \%$ of screen-detected cancers were found in non-smokers. The group surmised that an observed reduction in lung cancer mortality among Hitachi residents was due, at least in part, to the effect of $\mathrm{CT}$ screening on lung cancer mortality among non-smokers. The selection criteria for selected populations in recent trials of lung screening with LDCT are summarised in Table I.

\section{CHALLENGES}

Fundamental differences in lung cancer epidemiology between Singapore and Western populations

Recent data has emerged from Asia-Pacific countries, and from Singapore in particular, that demonstrates an alarming disparity in lung cancer patterns compared to Western countries. A strikingly high proportion of lung cancer was detected among neversmokers (47.7\% from local data in 2011), compared to data from Western countries, where the proportion of lung cancer among never-smokers was much lower at 10\%-15\%. ${ }^{(24)}$

Another large discrepancy is the greater incidence of adenocarcinoma $(77.6 \%$ from local data in 2011) in the local population compared to rates of adenocarcinoma in the US (38.5\%) and other Western countries. ${ }^{(25,26)}$ This reflects the AsiaPacific trend of higher rates of adenocarcinoma, particularly in women. ${ }^{(27-32)}$ Although local data trends are still currently being studied, there may be evidence of a fundamental difference in genetic predisposition among Chinese non-smokers, in addition to the effects of exposure to environmental risk factors. ${ }^{(5,27-52)}$ The link between adenocarcinoma of the lung and never-smoker status is also likely to play a role, based on the observation that adenocarcinoma is more common in never-smokers. ${ }^{(33-35,38,39,41,44)}$

\section{False positives and complications during workup}

The NLST defined any non-calcified nodule with a maximum diameter $\geq 4 \mathrm{~mm}$ as a positive screening result, which subsequently led to a large number of false-positive scans. A total of $27 \%$ of scans in the first two screening rounds were positive. ${ }^{(7)}$ The NELSON and some other European trials used a much higher threshold of approximately $10 \mathrm{~mm}$ in diameter (50 $\mathrm{mm}^{3}$ volume) for a positive screening result, but also established an indeterminate group of nodules measuring $5-10 \mathrm{~mm}$ in diameter $\left(50-500 \mathrm{~mm}^{3}\right.$ volume) that required earlier follow-up than the yearly screening interval. These nodules were considered a positive screening result only if significant growth (> 25\% volume change) was found. ${ }^{(15,19)}$ By using this approach, the number of scans with positive screening results was reduced from $27 \%$ in the NLST to $2.7 \%$ in the NELSON study.

The invasive diagnostic workup of small nodules includes bronchoscopy, which is limited by the location of the nodule. For some peripheral nodules (> $1 \mathrm{~cm})$, transthoracic CT-guided biopsy or resection by video-assisted thoracoscopic surgery is recommended. The risk of serious complications such as pneumothorax requiring drainage, infection or haemorrhage depends on the patient's underlying functional status and varies according to the centre.

\section{Overdiagnosis of lung cancer}

Overdiagnosis may be defined as detection of small lesions that are confirmed to be malignant but do not grow, spread or cause death. It includes individuals who die from other causes apart from lung cancer. This may cause harm during screening, in the form of additional cost, anxiety and morbidity associated with cancer diagnosis and treatment. 
Table I. Summary of selection criteria, follow-up duration and number of enrolled individuals of several major trials.

\begin{tabular}{|c|c|c|c|}
\hline \multirow[t]{2}{*}{ Study } & \multicolumn{2}{|r|}{ Selection criteria } & \multirow{2}{*}{$\begin{array}{l}\text { No. of patients screened; } \\
\text { follow-up duration }\end{array}$} \\
\hline & Age (yr) & Tobacco smoking; delay since weaning & \\
\hline DLCST & $50-70$ & $\geq 20$ pack-yr; 0-9 yr & 2,$052 ; 58 \mathrm{mth}$ \\
\hline DANTE & 60-74 (only men) & $\geq 20$ pack-yr; 0-9 yr & 1,$276 ; 34 \mathrm{mth}$ \\
\hline ITALUNG & $55-69$ & $\geq 20$ pack-yr (active/former) & 1,$406 ; 36 \mathrm{mth}$ \\
\hline \multirow[t]{2}{*}{ MILD } & \multirow[t]{2}{*}{$\geq 49$} & \multirow[t]{2}{*}{$\geq 20$ pack-yr; 0-9 yr } & 1,190 annual CT; 120 mth \\
\hline & & & 1,186 biannual CT; 53 mth \\
\hline NELSON & $50-75$ & $\geq 15$ pack-yr $; 0-9 y r$ & 7,$907 ; 60 \mathrm{mth}$ \\
\hline NLST & $55-74$ & $\geq 30$ pack-yr; 0-15 yr & 26,$722 ; 78$ mth \\
\hline UKLS & $50-75$ & $\begin{array}{l}\text { A 5-yr lung cancer risk of } \geq 5 \% \text {, based on the } \\
\text { Liverpool lung project } v 2 \text { risk prediction model }\end{array}$ & 4,$055 ; 12$ mth \\
\hline HITACHI* & $50-69$ & Smokers and never-smokers & 31,$739 ; 14 \mathrm{yr}$ \\
\hline $\mathrm{TAO}^{+}$ & $40-74$ & Smokers and never-smokers & 5,$483 ; 36 \mathrm{mth}$ \\
\hline
\end{tabular}

*Hitachi, Ibaraki, Japan. †Telecommunications Advancement Organization (TAO) of Japan, Matsumoto Research Centre. $¥ N E L S O N$ inclusion criteria: number of cigarettes smoked is $\geq 15$ per day for 25 years $O R \geq 10$ cigarettes per day for 30 years AND still smoking or having quit $<10$ years ago.

Currently, LDCT screening overdiagnosis rates are not available. The NLST data showed that the percentage of Stages IA and IB lung cancers detected by screening was high, which leads to the assumption that overdiagnosis may be a potential harm. However, mortality rates from lung cancer suggest that all histological foci of lung cancer pose a threat to health, regardless of their $\mathrm{CT}$ phenotype or how they are discovered.

\section{Radiation}

Current LDCT protocols enable scans to be performed at an effective dose of 1.0-1.7 mSv, based on local data. This translates to an approximate excess lifetime cancer risk that is estimated to be $0.02 \%$ in male smokers and $0.05 \%$ in female smokers at three yearly screening rounds. ${ }^{(20)}$ The risks did not increase whether the starting age for screening was 30,40 or 50 years, suggesting that radiation risk becomes important only if the pre-test risk for lung cancer is small. Since the baseline cancer risk is $0.8 \%-2.2 \%$ in the various screening trials, the risk-benefit ratio is in favour of screening over no screening. ${ }^{(20)}$

\section{Cost-effectiveness}

Data from the NLST demonstrated that lung screening in the US could be cost-effective, showing that screening for lung cancer, compared with no screening, is estimated to cost about USD 81,000 per quality-adjusted life-year (QALY) gained. ${ }^{(53)}$ Although no upper limit threshold for cost-effectiveness has been firmly established within the US, leading health economists have recommended a threshold between USD 100,000 and USD 150,000 per QALY gained.

A study from Japan ${ }^{(22)}$ demonstrated cost-effectiveness in a community-based lung cancer screening programme, with estimated costs of approximately USD 2,290 for women and USD 728 for men, respectively, to save one person-year in the 55-59 year-old cohort. The same study also calculated the cost of CT screening per person to be USD $50(5,000$ Japanese Yen).

\section{RECOMMENDED INCLUSION AND EXCLUSION CRITERIA FOR SINGAPORE LUNG CANCER SCREENING WITH CT}

Based on the aforementioned data from international and regional studies, we propose the following inclusion and exclusion criteria.

For high-risk groups, the inclusion criteria are: aged between 55 and 75 years, tobacco smoking history of at least 30 packyears, and current smoker or ex-smoker who quit smoking within the last 15 years. Once evidence is more robust, possible additional inclusion criteria are any of the following risk factors in never-smokers aged between 50 and 75 years: (a) never-smoker, female, east Asian (NESFEAS) phenotype; (b) family history of lung cancer; and (c) history of exposure to known carcinogens and air pollution.

Suggested exclusion criteria are comorbidities precluding therapy for further investigation and cure, and lack of consent for the same.

\section{SUGGESTIONS AND SOLUTIONS Multidisciplinary teams}

Multidisciplinary expertise is essential; accredited screening programmes would have access to a set of professionals, including radiologists, respiratory physicians, oncologists, pathologists and cardiothoracic surgeons.

\section{Combined smoking cessation programme}

A mandatory and concurrent smoking cessation programme would give access to trained staff who would provide effective smoking cessation advice and treatment, enabling the screening programme to reap the full benefits of further mortality reduction from all causes related to smoking as well as cost-effectiveness savings from tobacco abstinence. The overall impact of smoking on direct and indirect costs to healthcare spending in Singapore is estimated to be SGD 839 million, from the 2002 study mentioned earlier. ${ }^{(6)}$ 


\section{Risk model and broad screening}

Pre-test probability can be increased by using a risk model and considering additional risk factors, particularly the NESFEAS phenotype. This guideline proposes a unique approach that adopts additional inclusion criteria over previous guidelines, acknowledging evidence from Asian data that supports a fundamental difference in risk profile within the local population. It also considers data from Japanese LDCT screening studies that demonstrates the cost-effectiveness and mortality reduction of general screening of the population above a certain age ( 40 years and 50 years in two different studies), regardless of smoking history. ${ }^{(21,22)}$

The incidence of lung cancer in Japan is similar to that of Singapore, with an age-standardised incidence rate per 100,000 of 35.7 and 15.5 for male and female Singaporeans, and 38.8 and 12.9 for male and female Japanese, respectively, implying that it is a healthcare concern of similar importance. ${ }^{(4,5,45,46,54-56)}$ Notably, the gross domestic product per capita of Singapore exceeds that of Japan (Singapore 87,855 vs. Japan 41,275 international dollars).

\section{Standard workflow model}

Image acquisition, nodule evaluation, management of positive screen results, monitoring of false-positive results and procedural complications should be formalised into a standard operating procedure to ensure consistency and rigour in the application of guidelines. A dedicated workflow is required to provide seamless patient care from initial screen to biopsy and smoking cessation counselling.

\section{Computer-aided detection and deep learning algorithms}

Nodule evaluation and follow-up by computer-aided detection (CAD) and deep-learning algorithms are foreseen to become major components of any successful lung cancer screening programme in the future. ${ }^{(57-70)} \mathrm{A}$ major benefit of using deep-learning algorithms is the reduction in reliance on human labour, thereby increasing costeffectiveness. There are already studies showing that commercial CAD systems have excellent sensitivity for the detection of lung cancer nodules of at least $11 \mathrm{~mm}$ in size (sensitivity > 95.4\%). ${ }^{(68)}$

Although the Japanese, European and North American lung screening trials all demonstrated cost-effectiveness in their data, we propose that increased cost-effectiveness can be achieved with utilisation of deep-learning computer software. Software for automated detection of nodules is already available in the market, but further enhancement is required to automate decision-making for first-round screen-detected nodules, follow-up intervals for subsequent rounds and discharge from screening. Sensitivity and false positive rates have been shown to be improved by employing massive-training artificial neural networks, which are a form of deep-learning system. ${ }^{(63)}$ A human operator (i.e. radiologist) would only need to intervene once a nodule was flagged by the computer algorithm as suspicious, either due to the baseline size and appearance of the nodule during the first-round scan or a size/volume increase during the second-round scan. This significantly reduces the number of manpower hours expended and cost per screen.

\section{Radiation dose reduction}

Radiation burden reduction can be achieved by performing all screen studies with multidetector LDCT using at least 64 detector rows and isotropic high spatial resolution with a slice thickness of $1 \mathrm{~mm}$, achieving effective doses of 1-3 mSv.

Further dose reductions are now possible with improvements in $\mathrm{CT}$ technology. Using iterative reconstruction techniques and automated exposure control, radiation exposure can be substantially reduced by up to $80 \%$, to a level of $0.2 \mathrm{mSv}$ per study. ${ }^{(71-77)}$ This form of ultra-LDCT (ULDCT) with very low radiation doses is limited by poorer image quality in patients with high body mass index and poor assessment of ground glass nodules. ${ }^{(77)}$ Nonetheless, early studies have shown that there is no significant reduction in nodule detectability with ULDCT compared to usual LDCT. ${ }^{(73)}$

\section{Screening registry}

A national lung cancer screening registry should be established to collect submitted data from individual centres. This includes a biobank of pathological results and tumour markers, and a radiological image bank. The data would be used for longitudinal studies over a five- to ten-year period. Further studies of local data are required to examine the differences in cancer epidemiology and tumour receptor mutations among the local population of lung cancer patients compared to those from non-Asian countries.

\section{Future developments in biomarker screening}

Future developments in biomarker screening for lung cancer should be actively pursued and adopted into guidelines as soon as they become practically available. These include lung cancer biomarkers detected via breathalyser analysis, blood tests and urinalysis.

\section{Cost-benefit analysis}

Finally, a local cost-benefit analysis should be conducted in Singapore to evaluate the costs to implement this screening programme, both with and without deep-learning automation. This cost-benefit analysis would help institutions estimate the value and economic advantages of developing deep learning screening programmes for lung cancer.

\section{CONCLUSION}

The difference in patterns of lung cancer epidemiology between the local Singaporean population and European and North American cohorts necessitates an adaptive approach to lung cancer screening in Singapore. One particular group that has been identified to be at high risk in the local population is NESFEAS individuals.

This position paper proposes a practical, current and unique evidence-based approach to lung cancer screening to ensure a better fit for the local disease pattern. Multidisciplinary expertise is essential, and accredited screening programmes would have access to professionals including radiologists, respiratory physicians, oncologists, pathologists, nurse specialists and cardiothoracic surgeons. A dedicated workflow to provide 
seamless patient care from initial screen to biopsy and smoking cessation counselling would be required. After adoption of these guidelines, a comprehensive national lung cancer screening registry should be incorporated into the programme to monitor disease trends and provide robust evidence on efficacy.

\section{REFERENCES}

1. World Health Organization. World Cancer Report 2014. Available at: http:// www.who.int/cancer/publications/WRC_2014/en/. Accessed May 1, 2017.

2. National Registry of Diseases Office, Health Promotion Board, Singapore Singapore Cancer Registry Annual Registry Report Trends in Cancer Incidence in Singapore National Registry of Diseases Office (NRDO). Natl Regist Dis Off (NRDO) 2014; 61

3. Molina JR, Adjei AA, Jett JR. Advances in chemotherapy of non-small cell lung cancer. Chest 2006; 130:1211-9.

4. Siegel RL, Miller KD, Jemal A. Cancer statistics, 2017. CA Cancer J Clin 2017; 67:7-30.

5. Alberg AJ, Samet JM. Epidemiology of lung cancer. Chest 2003; 123(1 Suppl):21S-49S.

6. Yoong J. Why Singapore still needs tobacco control measures. The Straits Times 2015 Jun 3; Opinion Section. Available at: https://sph.nus.edu.sg/sites/ default/files/Why $\% 20$ Singapore $\% 20$ still\%20needs $\% 20$ tobacco $\% 20$ control $\% 20$ measures.pdf.

7. National Lung Screening Trial Research Team, Aberle DR, Berg CD, et al. The National Lung Screening Trial: overview and study design. Radiology 2011; 258:243-53

8. National Lung Screening Trial Research Team, Aberle DR, Adams AM, et al. Reduced lung-cancer mortality with low-dose computed tomographic screening N Engl J Med 2011; 365:395-409.

9. Aberle DR, DeMello S, Berg CD, et al; National Lung Screening Trial Research Team. Results of the two incidence screenings in the National Lung Screening Trial. N Engl J Med 2013; 369:920-31.

10. National Lung Screening Trial Research Team, Church TR, Black WC, et al Results of initial low-dose computed tomographic screening for lung cancer. N Engl J Med 2013; 368:1980-91.

11. Pinsky PF, Church TR, Izmirlian G, Kramer BS. The National Lung Screening Trial: results stratified by demographics, smoking history, and lung cancer histology. Cancer 2013; 119:3976-83.

12. Kramer BS, Berg CD, Aberle DR, Prorok PC. Lung cancer screening with lowdose helical CT: results from the National Lung Screening Trial (NLST). J Med Screen 2011; 18:109-11.

13. Field JK, Aberle DR, Altorki N, et al; International Association for the Study of Lung Cancer Strategic Screening Advisory Committee. The International Association Study Lung Cancer (IASLC) Strategic Screening Advisory Committee (SSAC) response to the USPSTF recommendations. J Thorac Oncol 2014; 9:141-3.

14. Moyer VA; US Preventive Services Task Force. Screening for lung cancer: U.S Preventive Services Task Force recommendation statement. Ann Intern Med 2014; 160:330-8.

15. Xu DM, Gietema $\mathrm{H}$, de Koning $\mathrm{H}$, et al. Nodule management protocol of the NELSON randomised lung cancer screening trial. Lung Cancer 2006; 54:177-84.

16. Infante M, Lutman FR, Cavuto S, et al; DANTE Study Group. Lung cancer screening with spiral CT: baseline results of the randomized DANTE trial. Lung Cancer 2008; 59:355-63.

17. Picozzi G, Paci E, Lopez Pegna A, et al. Screening of lung cancer with low dose spiral CT: results of a three year pilot study and design of the randomised controlled trial "Italung-CT". Radiol Med 2005; 109:17-26.

18. Infante M, Cavuto S, Lutman FR, et al; DANTE Study Group. A randomized study of lung cancer screening with spiral computed tomography: three-year results from the DANTE trial. Am J Respir Crit Care Med 2009; 180:445-53.

19. van lersel CA, de Koning HJ, Draisma G, et al. Risk-based selection from the general population in a screening trial: selection criteria, recruitment and powe for the Dutch-Belgian randomised lung cancer multi-slice CT screening tria (NELSON). Int J Cancer 2007; 120:868-74.

20. Kauczor HU, Bonomo L, Gaga M, et al; European Society of Radiology (ESR); European Respiratory Society (ERS). ESR/ERS white paper on lung cancer screening. Eur Radiol 2015; 25:2519-31.

21. Nawa T, Nakagawa T, Kusano $S$, et al. Lung cancer screening using low-dose spiral CT. Chest 2002; 122:15-20.

22. Sone S, Li F, Yang ZG, et al. Results of three-year mass screening programme for lung cancer using mobile low-dose spiral computed tomography scanner. Br J Cancer 2001; 84:25-32.

23. Nawa $T$, Nakagawa $T$, Mizoue $T$, et al. A decrease in lung cancer mortality following the introduction of low-dose chest CT screening in Hitachi, Japan. Lung Cancer 2012; 78:225-8.

24. Parkin DM, Pisani P, Lopez AD, Masuyer E. At least one in seven cases of cancer is caused by smoking. Global estimates for 1985. Int J Cancer 1994
59:494-504.

25. Alberg AJ, Brock MV, Samet JM. Epidemiology of lung cancer: looking to the future. J Clin Oncol 2005; 23:3175-85.

26. SEER Cancer Statistics Review, 1975-2008. In: National Cancer Institute [online]. Available at: https://seer.cancer.gov/archive/csr/1975_2008/. Accessed April 30, 2017.

27. Devesa SS, Bray F, Vizcaino AP, Parkin DM. International lung cancer trends by histologic type: male: female differences diminishing and adenocarcinoma rates rising. Int J Cancer 2005; 117:294-9.

28. Wu-Williams AH, Dai XD, Blot W, et al. Lung cancer among women in northeast China. Br J Cancer 1990; 62:982-7.

29. Seow A, Poh WT, Teh M, et al. Fumes from meat cooking and lung cancer risk in Chinese women. Cancer Epidemiol Biomarkers Prev 2000; 9:1215-21.

30. Charloux A, Quoix E, Wolkove N, et al. The increasing incidence of lung adenocarcinoma: reality or artefact? A review of the epidemiology of lung adenocarcinoma. Int J Epidemiol 1997; 26:14-23.

31. Zhou W, Christiani DC. East meets West: ethnic differences in epidemiology and clinical behaviors of lung cancer between East Asians and Caucasians. Chin J Cancer 2011; 30:287-92.

32. Bai C, Choi CM, Chu CM, et al. Evaluation of pulmonary nodules: clinical practice consensus guidelines for Asia. Chest 2016; 150:877-93.

33. Wakelee HA, Chang ET, Gomez SL, et al. Lung cancer incidence in never smokers. J Clin Oncol 2007; 25:472-8.

34. Rudin CM, Avila-Tang E, Harris CC, et al. Lung cancer in never smokers: molecular profiles and therapeutic implications. Clin Cancer Res 2009; 15:5646-61.

35. Planchard D, Besse B. Lung cancer in never-smokers. Eur Respir J 2015; 45:1214-7

36. Wu YL, Zhou Q. Lung cancer management in the Asia-Pacific region: what's the difference compared with the United States and Europe? Results of the Second Asia Pacific Lung Cancer Conference. J Thorac Oncol 2007; 2:574-6.

37. Donington JS, Le QT, Wakelee HA. Lung cancer in women: exploring sex differences in susceptibility, biology, and therapeutic response. Clin Lung Cancer 2006; 8:22-9.

38. Subramanian J, Govindan R. Lung cancer in 'never-smokers': a unique entity, Oncology (Williston Park) 2010; 24:29-35.

39. Yano T, Miura N, Takenaka T, et al. Never-smoking nonsmall cell lung cancer as a separate entity: clinicopathologic features and survival. Cancer 2008; 113:1012-8.

40. Gao YT, Blot WJ, Zheng W, et al. Lung cancer among Chinese women. Int J Cancer 1987; 40:604-9.

41. Toh CK, Lim WT. Lung cancer in never-smokers. J Clin Pathol 2007; 60:337-40.

42. Hoover RN. Cancer--nature, nurture, or both. N Engl J Med 2000; 343:135-6.

43. Toh CK, Ahmad B, Soong R, et al. Correlation between epidermal growth factor receptor mutations and expression of female hormone receptors in East-Asian lung adenocarcinomas. J Thorac Oncol 2010; 5:17-22.

44. Sun S, Schiller JH, Gazdar AF. Lung cancer in never smokers--a different disease. Nat Rev Cancer 2007; 7:778-90.

45. Cheng TY, Cramb SM, Baade PD, et al. The international epidemiology of lung cancer: latest trends, disparities, and tumor characteristics. J Thorac Oncol 2016; 11:1653-71.

46. Funatogawa I, Funatogawa T, Yano E. Trends in smoking and lung cancer mortality in Japan, by birth cohort, 1949-2010. Bull World Health Organ 2013; 91:332-40.

47. Mitsudomi T, Kosaka T, Yatabe Y. Biological and clinical implications of EGFR mutations in lung cancer. Int J Clin Oncol 2006; 11:190-8.

48. Bell DW, Brannigan BW, Matsuo K, et al. Increased prevalence of EGFR-mutant lung cancer in women and in East Asian populations: analysis of estrogen-related polymorphisms. Clin Cancer Res 2008; 14:4079-84.

49. Shi Y, Li J, Zhang S, et al. Molecular epidemiology of EGFR mutations in Asian patients with advanced non-small-cell lung cancer of adenocarcinoma histology - mainland China subset analysis of the PIONEER study. PLoS One 2015; 10:e0143515.

50. Milanezi F, Carvalho S, Schmitt FC. EGFR/HER2 in breast cancer: a biological approach for molecular diagnosis and therapy. Expert Rev Mol Diagn 2008; 8:417-34.

51. Shigematsu $H$, Takahashi $T$, Nomura $M$, et al. Somatic mutations of the HER2 kinase domain in lung adenocarcinomas. Cancer Res 2005; 65:1642-6.

52. Shi Y, Au JS, Thongprasert S, et al. A prospective, molecular epidemiology study of EGFR mutations in Asian patients with advanced non-small-cell lung cancer of adenocarcinoma histology (PIONEER). J Thorac Oncol 2014; 9:154-62.

53. Black WC, Keeler EB, Soneji SS. Cost-effectiveness of CT screening in the National Lung Screening Trial. N Engl J Med 2015; 372:388.

54. Youlden DR, Cramb SM, Baade PD. The International Epidemiology of Lung Cancer: geographical distribution and secular trends. J Thorac Oncol 2008; 3:819-31.

55. Islami F, Torre LA, Jemal A. Global trends of lung cancer mortality and smoking prevalence. Transl Lung Cancer Res 2015; 4:327-38.

56. Parkin DM, Bray F, Ferlay J, Pisani P. Global cancer statistics, 2002. CA Cancer J Clin 2005; 55:74-108. 
57. Sahiner B, Chan HP, Hadjiiski LM, et al. Effect of CAD on radiologists' detection of lung nodules on thoracic CT scans: analysis of an observer performance study by nodule size. Acad Radiol 2009; 16:1518-30.

58. Armato SG 3rd, Giger ML, MacMahon H. Automated detection of lung nodules in CT scans: preliminary results. Med Phys 2001; 28:1552-61.

59. Li Q. Recent progress in computer-aided diagnosis of lung nodules on thinsection CT. Comput Med Imaging Graph 2007; 31:248-57.

60. McCulloch CC, Kaucic RA, Mendonça PR, Walter DJ, Avila RS. Model-based detection of lung nodules in computed tomography exams. Thoracic computeraided diagnosis. Acad Radiol 2004; 11:258-66

61. Gurcan MN, Sahiner B, Petrick N, et al. Lung nodule detection on thoracic computed tomography images: preliminary evaluation of a computer-aided diagnosis system. Med Phys 2002; 29:2552-8.

62. Roos JE, Paik D, Olsen D, et al. Computer-aided detection (CAD) of lung nodules in CT scans: radiologist performance and reading time with incremental CAD assistance. Eur Radiol 2010; 20:549-57.

63. Suzuki K, Armato SG 3rd, Li F, Sone S, Doi K. Massive training artificial neural network (MTANN) for reduction of false positives in computerized detection of lung nodules in low-dose computed tomography. Med Phys 2003; 30:1602-17.

64. Arimura H, Katsuragawa S, Suzuki K, et al. Computerized scheme for automated detection of lung nodules in low-dose computed tomography images for lung cancer screening. Acad Radiol 2004; 11:617-29.

65. Beigelman-Aubry C, Raffy P, Yang W, Castellino RA, Grenier PA. Computeraided detection of solid lung nodules on follow-up MDCT screening: evaluation of detection, tracking, and reading time. AJR Am J Roentgenol 2007; 189:948-55

66. Beyer F, Zierott L, Fallenberg EM, et al. Comparison of sensitivity and reading time for the use of computer-aided detection (CAD) of pulmonary nodules a MDCT as concurrent or second reader. Eur Radiol 2007; 17:2941-7.

67. Jankowski A, Martinelli T, Timsit JF, et al. Pulmonary nodule detection on
MDCT images: evaluation of diagnostic performance using thin axial images, maximum intensity projections, and computer-assisted detection. Eur Radiol 2007; 17:3148-56.

68. Godoy MC, Cooperberg PL, Maizlin ZV, et al. Detection sensitivity of a commercial lung nodule CAD system in a series of pathologically proven lung cancers. J Thorac Imaging 2008; 23:1-6.

69. Marten K, Engelke C. Computer-aided detection and automated CT volumetry of pulmonary nodules. Eur Radiol 2007; 17:888-901.

70. Rubin GD, Lyo JK, Paik DS, et al. Pulmonary nodules on multi-detector row CT scans: performance comparison of radiologists and computer-aided detection. Radiology 2005; 234:274-83.

71. Katsura M, Matsuda I, Akahane M, et al. Model-based iterative reconstruction technique for ultralow-dose chest CT: comparison of pulmonary nodule detectability with the adaptive statistical iterative reconstruction technique. Invest Radiol 2013; 48:206-12.

72. Nitta N, Takahashi M, Murata K, Morita R. Ultra low-dose helical CT of the chest: evaluation in clinical cases. Radiat Med 1999; 17:1-7.

73. Lee JY, Chung MJ, Yi CA, Lee KS. Ultra-low-dose MDCT of the chest: influence on automated lung nodule detection. Korean J Radiol 2004; 9:95-101.

74. Baumueller S, Winklehner A, Karlo C, et al. Low-dose CT of the lung: potential value of iterative reconstructions. Eur Radiol 2012; 22:2597-606.

75. Silva AC, Lawder HJ, Hara A, Kujak J, Pavlicek W. Innovations in CT dose reduction strategy: application of the adaptive statistical iterative reconstruction algorithm. AJR Am J Roentgenol 2010; 194:191-9.

76. Singh S, Kalra MK, Gilman MD, et al. Adaptive statistical iterative reconstruction technique for radiation dose reduction in chest CT: a pilot study. Radiology $2011 ; 259: 565-73$.

77. Lee SW, Kim Y, Shim SS, et al. Image quality assessment of ultra low-dose chest CT using sinogram-affirmed iterative reconstruction. Eur Radiol 2014; 24:817-26. 